[TS: set copyright line as CThe Author(s) 2020]

From the James Lind Library

\title{
The French road to Gavarret's clinical application of probabilistic thinking: Part 1 French dramatis personae
}

\section{Introducing French dramatis personae}

Let me begin with four outstanding French scientists, born in the $1740 \mathrm{~s}$, who knew each other and who all felt that an interest in the evaluation of a therapy would be best satisfied by calculating the probability of its success.

Antoine de Lavoisier (b.1743) was to become one of the most renowned scientists in Europe. Although primarily an experimental chemist (who discovered oxidation), he was also an economist, and an aristocratic high official (a toll collector and therefore beheaded during the French revolution). In the mid-1760s already, precisely when issues of probabilism were debated in the Académie des Sciences, he sought for membership of this eminent body. In his recorded works we find, undated, but probably around 1784, a note that is worth quoting at length:

The art of drawing conclusions from experiments and observations consists in evaluating the probabilities, and in judging whether they are large enough, or numerous enough, to amount to proof. This type of calculation is 
more complicated and more difficult than one thinks; it demands great sagacity and is, in general, beyond the powers of most men. It is upon their errors in this type of calculation that is founded the success of charlatans, sorcerers and alchemists ... and, generally, of all those who deceive themselves or attempt to prey on the credulity of the public.

And he continued even more specifically, maybe in remembrance of the Bernoulli - d'Alembert debate of which he must have been aware:

It is above all in medicine that the difficulty of evaluating the probabilities is greater ... Nature, left to its own resources, cures a large number of maladies; when remedies are employed it is infinitely difficult to determine what is due to Nature and what to the remedy. Thus, for all that most people regard the cure of a disease as a proof of the efficacy of the remedy, in the eyes of a wise man this result is only a probability, more or less large, and this probability cannot be converted into certainty except by a large number of results of the same kind (Transl. by IML Donaldson from Lavoisier 1865, p 509; Donaldson 2016; Donaldson 2016 a).

And so it truly is. Handling probability is indispensable, but, as we shall see, doctors took a long time to understand this.

Scientists were more progressively minded, at least in their statements, the calculus of probabilities awaked the interest of French mathematicians, one of whom was also a clinician.

Marie-Jean-Antoine Nicolas de Condorcet (b.1743) was an aristocrat who had published several noteworthy mathematical contributions, including on the calculus of probabilities. He became an important official (Inspecteur Général de la Monnaie) and Perpetual Secretary of the Académie des Sciences.

Jacob Bernoulli's early call for a science of decision-making influenced him and in his Essai sur l'application de l'analyse à la probabilité des décisions rendues à la pluralité des voix (Essay 
on the application of probability theory to decision making by majority vote, 1785) he argued how and why probability theory should also serve in political and social life. His 1785 Essai was Condorcet's most sophisticated mathematical undertaking. He attempted to set down the rules needed to calculate the veracity of decisions affecting a variety of civic values and matters of criminal justice.

Formerly, probability theory had proven its worth in estimating life annuities or rates of maritime insurance. Now, Condorcet argued, calculation could also serve in an entirely different domain, the operations of the human mind, "where it weighs the grounds for belief and calculates the probable truth of testimony or decisions", that is, the consequences of decisions. Events in pre-revolutionary France, prompted by passion and factionalism, proved the need for such a guide. Though never completed, this "social mathematics" remained a part of Condorcet's legacy to mathematicians, social theorists and it influenced some members of the medical profession (Daston 1995, pp 210-224).

Philippe Pinel (b.1745), the reformer of French psychiatry, a fine clinician and chief of psychiatric hospitals in Paris, was a mythical figure in his lifetime for allegedly liberating psychiatric patients from their chains (Weiner 2007). He also held a diploma in mathematics. In his Traité medico-philosophique de l'aliénation mentale (1800) (A treatise on insanity, also published in an incomplete English edition in 1806), he wrote:

To be authentic and conclusive, an experiment must involve a large number of patients submitted to general rules and treated according to a determined order...

Finally, favourable as well as unfavourable events have to be reported [from the experiment] so that we can learn from both. That is to say, if one wants to establish treatment methods for disease on solid foundations, they must use the theory of probabilities, which is already happily applied to various fields of civic life (Transl. from Pinel 1809, pp 402-403). 
Pinel's reference to the application of probabilities to "various fields of civic life" was an allusion to Bernoulli's Ars conjectandi (which he erroneously attributed to Daniel Bernoulli). Finally, he specified that numerical data were needed to compare two competing methods of medical treatment ( $p$ 406-407) and concluded: "...it is necessary to apply the elementary notions of the calculus of probabilities" ( $p$ 424). As an illustration, he used data obtained at La Salpétrière psychiatric hospital in Paris and calculated the proportions of various groups of patients who had recovered. Put simply, he compared these probabilities, albeit not by defining the groups by the treatments they had received (Sheynin 1982, p 250).

Pinel repeated the same thoughts and data in a paper published in 1807:

Medicine must be based on the theory of probabilities ... on which the methods of treating disease has henceforth to be founded if one wants to establish them on solid grounds.

In the same paper he complained about the habit of suppressing unsuccessful cases, thus preventing medicine from acquiring the character of a true science, an achievement it will only attain through the application of the calculus of probabilities (Transl. from quotes in Sheynin 1982, p 250. Dickersin, Chalmers 2010; Bird 2018; Bishop, Gill 2019).

Here we have further examples of conscious, yet premathematical probabilistic reasoning. Others were soon to follow. Despite their reiteration, however, Pinel's references to probability were mere words, a loose allusion, implying no more than calculating proportions. His work contains no example of the application of the calculus of probabilities. Finally, as shown in Part 1of this manuscript, his method did not differ from that of Jurin. Practical limitations, such as wide dissimilarity of his case histories, restricted the application of quantitative evaluations. 
However, the contributions of French mathematicians, such as those of Laplace and Poisson, continued to assert the potential usefulness of probabilistic approaches to clinical medicine.

Pierre Simon de Laplace (b.1749) was the foremost French mathematician, physicist and astronomer of his day and remains one of the great scientists of all times; his pupil Poisson called him "the French Newton" (Stigler 1986, p 31). Laplace was one of the founding fathers of probability theory, and the Bayesian interpretation of probability was developed mainly by him (Stigler 1986, chapter 3). The mathematicianhistorian Robert Matthews will discuss Bayes's theorem, a particular approach of statistical inference, in a forthcoming paper.

In some lectures given in 1795, Laplace reaffirmed Condorcet's optimism concerning social mathematics: "Let us apply to the political and moral sciences the method founded upon observation and calculation, which has served us so well in the natural sciences." Yet, echoing Jacob Bernoulli, he was sceptical about their usefulness because of passions and self-interests involved in decision-making in these fields. As the medical historian Terence Murphy has noted, Laplace sensed that "...the more vital the issue, the more likely are vested interests to counter the voice of reason", so it was useless to use the calculus of probabilities to determine the truth of such decisions. Yet he hoped for its valuable use in the future (Murphy 1981, p 305). He expressed this in two, albeit short, passages within two works.

Laplace explicitly mentioned therapeutics in his Théorie analytique des probabilités (Analytical theory of probabilities, 1812):

The calculus of probabilities can make us appreciate the advantages and inconveniencies of the methods employed in the conjectural sciences. Thus, in order to recognize the best treatment in healing an illness it suffices to try each of them on the same number of patients while keeping all the circumstances perfectly alike. The superiority of the 
most advantageous treatment will be manifested more and more as the number of cases increases; and the calculus [of probabilities] will make known the probability corresponding to its [the treatment's] advantage (Transl. from de Laplace 1820, p LXXVII).

Thus, the calculus would make known probability corresponding to a treatment's] advantage, as long as there were sufficient cases and an unvarying relationship between treatment and outcome exists - which did not reflect doctors' experiences/ expectations.

His Essai philosophique sur les probabilités (Philosophical essay on probabilities 1814) was the Introduction to the Théorie analytique, added to its later editions, but it was also published separately. As such it contains no mathematical formulae; it typically opens with a general statement:

One may even say, strictly speaking, that almost all our knowledge is only probable; and in the small number of things that we are able to know with certainty, is the mathematical sciences themselves. The principal means of arriving at the truth - induction and analogy - are based on probabilities (de Laplace 1995, p 1).

Although he further wrote that "the theory of probabilities is fundamentally only good sense reduced to calculation", Laplace wanted to submit intuitive judgments to the rigors of analysis.

His clear, consciously formulated plea for the use of formal probability in therapeutic evaluation underestimated the difficulty resulting from his requirement for "a sufficient number" (Sheynin 1978, p 285), after realizing that, for the time being, the number was beyond a doctor's competence. Furthermore, the calculations assumed a constant relation between causes and observed putative effects. This inherent constant relation would have troubled physicians. In fact, whether numerical methods could actually influence the choice of a remedy was not raised, and Laplace himself never applied 
the calculus of probabilities to medical phenomena (Murphy 1981).

Laplace's Théorie was extremely influential. Not only did it have six contemporary editions, but it was translated into English (1820), German (1820), and Dutch (18...?); and it is still in print in many languages. Yet, mathematically speaking, theory of probability stagnated because new fields of application (physics, biology) had not yet appeared. Furthermore, his book was difficult to read. Almost the only mathematician elaborating on Laplace's work during this period was his pupil, Siméon Denis Poisson, 32 years his junior (Sheynin 1976, pp 179-180). (I shall discuss him later in Part 2/2 of this series).

In fact, at the end of the $18^{\text {th }}$ and beginning of the $19^{\text {th }}$ centuries, contemporaries agreed that observation and "experience" were the basis of sound therapeutics (Murphy 1981, p 309). But experience could have many meanings. In French medical journals and Dictionaires it might include, during these decades, subjective opinions, beliefs, based on single case descriptions or on extended follow-up, as well as hospital data. Furthermore, statistical work on social groups (which would become public health) was flourishing in France in the 1820s. Not until the mid-1830s, however, were methodological issues about quantitative comparisons in the evaluation of therapies debated - in Paris, of course.

\section{Unconscious probabilists}

I came across two remarkable French authors of very diverse social standing who remain unnoticed, not only in relation to their probabilistic thinking in medicine. Neither of them seems to have been aware that he was a probabilist.

In the early $18^{\text {th }}$ century the question whether an absolutely necessary amputation had to be performed as soon as possible after an injury or after a few days' delay had been preoccupying surgeons for some time. Theoretically you could argue for or against both methods. An ordinary mid- $18^{\text {th }}$ century army surgeon, decided to solve the question using a trial. An army surgeon named JF Faure, whose Christian 
names and date of birth I was unable to find, described the experiment in detail:

[This experiment was done] in the hope that we would have a less equivocal success and also in order to affirm the principles by tests repeated sufficiently to overcome the disbelief of the most prejudiced. Ten English wounded, out of a number of about one thousand who had been taken to the hospitals of Douay after the battle of Fontenoy [1745], were therefore set aside. Their wounds were such that amputation was essential in most of them... It was simply a question of whether the amputation was carried out sooner or later (Transl. from Faure 1759, p 353).

All ten survived. Faure compared this outcome to the overall mortality of those who had received immediate amputation. Adducing further testimonies and numbers he calculated the chance of healing: It amounted to nine out of ten after delayed intervention, and to between one in ten and one in three after immediate amputation. He concluded that "it seemed to me difficult not to be impressed by an experiment repeated ten times and always with the same success" and he sent a "Mémoire" to the French Académie Royale de Chirurgie (Faure 1759).

The Academy's decision of to award its 1754 annual prize to Faure made delayed amputation respectable. But the issue continued to be debated on the same basis of retro-and prospective trials for another hundred years, particularly from German and British military statistics (Tröhler 2000).

My second example of an unconscious probabilist is the distinguished surgeon Baron Anthelme-Balthasar Richerand (b.1779). He was of provincial stock. After moving to Paris he became a protégé of Cabanis. His word was influent, for he authored a textbook of physiology (ten editions), then was chief surgeon of the Hôpital St.Louis, a co-founder of the Académie de Médecine (1820), and finally wrote popular texts on medicine. 
Richerand proposed a solution for a seven-decade dispute about the treatment of cataract. Couching (i.e. displacement) of the opaque lens had been the standard therapy since Antiquity, and a problem arose when Jacques Daviel (b.1683 or 1693?) published his method for extracting the lens in 1753). Supporters of each method had fought on the basis of case series.

In his Des progrès récens [sic!] de la chirurgie (Recent advances in surgery, 1825) Richerand dealt with the uncertainty hovering above various approaches to treating illnesses. He observed that treatments for cataract in particular "still divide the supporters of extraction and couching of the lens" [author's italics]. But there was "only one way open to provide an escape from this maze of contradictory opinions and to resolve this important point in surgical doctrine". And this was, in today's terms, a prospective trial, comparing simultaneously "a certain number of patients" placed in the same circumstances, then operated on comparatively under the eyes of the Academy.

[For] an academic body alone, the sole interest of which is that of truth, is able to undertake and follow up such an experiment. Even the most able surgeon, and who in exercising his art aims at the truth with the greatest honesty and good faith, would be unable to defend himself against a multitude of prejudices, the existence and power of which he often ignores. Thence, what credibility can one attribute to those men of bad faith, for whom truth is nothing other than fashion acquired by misrepresentation? And what have we to understand by what they name their 'successes' by the use of this or that method? (Transl. from Richerand 1825, p 27).

Richerand did not mention a single word about the probability involved as a representation of the much-maligned uncertainty. We would say the above was the outline of a protocol for a prospective controlled clinical trial, albeit, without randomization, specification of outcome or method of analysis. No trial appears to have taken place, but ten years later, some of Richerand's colleagues from the Royal Academy discussed it 
- without quoting him - and concluded that they had settled the debate.

\section{Defence of the status quo}

Pierre-Jean-Georges Cabanis (b.1757), a Paris physician and hospital administrator, was also a theoretician at the height of the currents of his time. He formulated earlier reactions to quantitative techniques in his Du degré de certitude de la médecine (On the degree of certainty in medicine, 1798), written in 1788. Cabanis referred to d'Alembert and Condorcet (a friend) when he wrote "Each science has its own kind of proofs": A "happy instinct", i.e. a non-quantifiable talent, a kind of "sympathie morale", allowed a doctor to choose. In effect, Cabanis was defending the anarchic status quo of clinical practice. He remained attached to the idea that medical practice had a specific nature. This ruled out any formal alliance with the natural sciences and justified claims for criteria of medical knowledge independent of any formal standards established in other fields of human enquiry (Murphy 1981, Canguilhem 1970). His book, translated into German (1799) and English, was widely distributed, including in America. It was an early expression of the later widely held feeling among doctors that there should be no 'strangers' (that is, mathematicians) at the bedside, encroaching on the 'sacred' field of medicine. This feeling found expression in two academic debates two decades later.

(To be continued)

\section{Declarations}

Competing interests: None declared.

Funding: None declared.

Ethics approval: Not applicable.

Guarantor: UT.

Contributorship: Sole authorship.

Acknowledgements: None.

Provenance: Invited contribution from the James Lind Library.

Note

a. The references listed below are chosen as essential to the reading of the article. However, the full list of primary and secondary references is available online both on the Journal's website as supplementary material, and with the original publication at https://www.jameslindlibrary. 
org/articles/probabilistic-thinking-and-the-evaluationof-therapies-1700-1900/. Except when otherwise mentioned, translations into English are my own.

References in order of appearance

Donaldson IML ed (2016). Lavoisier's unpublished writings on animal magnetism, from Oeuvres de Lavoisier, T.III, with a page-by-page English translation by IML Donaldson. Edinburgh.

Donaldson IML (2016a). Antoine de Lavoisier's role in designing a single-blind trial to assess whether 'Animal Magnetism' exists. JLL Bulletin: Commentaries on the history of treatment evaluation (https://www.jameslindlibrary.org/articles/antoine-de-lavoisiers-role-indesigning-a-single-blind-trial-to-assess-whether-animal-magnetism-exists/).

Daston L (1995). Classical probability in the enlightenment. Princeton NJ: Princeton University Press.

Weiner DB (2007). Pinel, Philippe. In: Bynum WF and Bynum H (eds).

Dictionary of Medical Biography. Westport-London: Greenwood Press 4; 10081013.

Sheynin OB (1982). On the history of medical statistics. Archive for History of Exact Sciences 26: 241-286.

Stigler SM (1986). The history of statistics. Cambridge-London: Belknap Press of Harvard University Press, pp 62-70.

Murphy TD (1981). Medical knowledge and statistical methods in early nineteenth century France. Medical History 25: 301-319.

Sheynin OB (1976). P.S. Laplace's work on probability. Archive for History of Exact Sciences 16: 137-187.

Tröhler U (2000). 'To improve the evidence of medicine'. The 18th century British origins of a critical approach. Edinburgh: Royal College of Physicians.

Staum MS (2007). Cabanis, Pierre-Jean-Georges. In: Bynum WF and Bynum $\mathrm{H}$ (eds). Dictionary of Medical Biography. Westport, Conn. - London, Greenwood Press 2; 289-290). 
Canguilhem, G (1970-1980). Cabanis, Pierre-Jean-Georges. In: Dictionary of Scientific Biography. New York: Charles Scribner's Sons, vol 3: 1-3.

For a recent general orientation consult

Matthews RAJ (2020a). The origins of the treatment of uncertainty in clinical medicine. Part 1: Ancient roots, familiar disputes. JLL Bulletin: Commentaries on the history of treatment evaluation

(https://www.jameslindlibrary.org/articles/the-origins-of-thetreatment-of-uncertainty-in-clinical-medicine-part-1-ancientroots-familiar-disputes/).

Matthews RAJ (2020b). The origins of the treatment of uncertainty in clinical medicine. Part 2: the emergence of probability theory and its limitations. JLL Bulletin:

Commentaries on the history of treatment evaluation (https://www.jameslindlibrary.org/articles/the-origins-of-thetreatment-of-uncertainty-in-clinical-medicine-part-2-theemergence-of-probability-theory-and-its-limitations/). 